RESEARCH ARTICLE

\title{
Integrated Advanced Oxidation Process for the Treatment of Pharmaceutical Effluent
}

\author{
Baskaran $\mathbf{S}^{1}$, Paul Sebastian $\mathbf{S}^{\mathbf{2}}$, Sadish Oumabady ${ }^{3}$, Davamani $\mathbf{V}^{\mathbf{1}}$ and Kalaiselvi $\mathbf{P}^{\mathbf{1}}$ \\ ${ }^{1}$ Department of Environmental Sciences, Tamil Nadu Agricultural University, Coimbatore 641003, India \\ ${ }^{2}$ Anbil Dharmalingam Agricultural College and Research Institute, Tamil Nadu Agricultural University, Tiruchirappalli 620009, India \\ ${ }^{3}$ Department of Environmental Science, Dr Yashwant Singh Parmar University of Horticulture and Forestry, Solan 173230, India
}

\begin{abstract}
Increased exploitation of water resources by the industries has attained a level of saturation denoting the complete exploitation of water in the near future. The organic contaminants in the pharmaceutical effluent remain partially degraded at the end of conventional wastewater treatment technologies thereby posing a challenge. Electrochemical Oxidation and UV Oxidation processes have proven to be effective in treating these type of contaminants in the pharmaceutical effluents. This study focuses on the integration of Electrochemical and UV Oxidation in the presence of Fenton's reagent for the effective treatment of pharmaceutical contaminants. It has been observed that the maximum reduction (>90\%) of Chemical Oxygen Demand (COD) and Total Organic Carbon (TOC) was achieved during the combination of Electrochemical and UV Oxidation in the presence of 500 $m g \mathrm{~L}^{-1}$ Fenton's reagent.
\end{abstract}

Keywords: Electrochemical oxidation; Photo-chemical oxidation; Pharmaceutical effluent; Chemical oxygen demand

\section{INTRODUCTION}

In the era of the modern industrial revolution, there has been an intensive deterioration of natural resources that include air, water, and soil. In rivers and lakes that receive wastewater, pharmaceuticals are often found in concentrations of $0.1 \mu g \mathrm{~L}^{-1}$ to 1.0 $\mu g \mathrm{~L}^{-1}$ (Frank-Andreas Weber, 2014). The effluent from pharmaceutical industries has shown an increased concern because of the contaminants that prevail even after conventional wastewater treatments (Domínguez et al., 2011). Water has been polluted from both point source and nonpoint source of pollutants. These pollutants may be of organic or inorganic form (Gadipelly et al., 2014). Pharmaceutical effluent primarily consists of disposed antibiotics, analgesics, and other chemical substances that can persist in the environment over some time. As a result, these compounds enter humans through the food chain, thereby producing antibiotic resistance with the higher vulnerability of disease incidence (Moreira et al., 2017).

Despite implementing conventional treatment technologies, there is always a portion of pollutants that remains undisturbed without degradation, prevailing as a critical factor in deciding the quality of water (Garcia-Segura et al., 2018). Various stimulated research activities have resulted in introducing a process named as advanced oxidation process. Advanced oxidation process has derived as an efficient technology in treating wastewater wherein both the organic and inorganic forms of pollutants have been removed to an extent possible (Nidheesh et al., 2018). The advanced oxidation process involves the production of highly reactive hydroxyl radicals as intermediates that help in the destruction of target pollutants (Moreira et al., 2017). As a result of which, the organic form of pollutants will be oxidized and finally gets converted to carbon dioxide, water, and inorganic forms, wherein, the latter is removed by electrochemical methods.

AOPs.OH + Pollutants $\rightarrow \mathrm{CO}_{2}+\mathrm{H}_{2} \mathrm{O}+$ Inorganic Compounds

Various advanced oxidation process includes photo catalysis, Ozone Oxidation, UV Oxidation, Fenton and Photo-Fenton Oxidation. The removal efficiency of $86 \%$ COD and $90 \%$ turbidity by using $\mathrm{UV} / \mathrm{H}_{2} \mathrm{O}_{2}$ works best for wastewater with a high concentration of refractory chemicals (Boroski et al., 2009). Similar trends were obtained in the utilization of photo-Fenton oxidation with a retention time above 120 minutes (Kulik et al., 2008). The process was capable of achieving satisfactory levels of TOC removal at short treatment times (Domínguez et al., 2011). Every day, about $500 \mathrm{~m}^{3}$ of wastewater with high COD and BOD due to organic vapor contaminations have been 
released as effluent. This water is also used as a coolant due to low inorganic salt concentration but it is inhibited by organic contamination. So, this denotes the necessity for removing the latter contaminants from the wastewater. This study ends up in checking the effectiveness of Electro-oxidation and UV oxidation, particularly focused on removing COD and TOC from the pharmaceutical effluent. The treated effluent contains mineralized forms of nutrients that were released due to the degradation of organic contaminants, which can be recovered using nutrient recovery technologies (Huang et al., 2020). Recently, nutrient recovery technologies using adsorbent materials have gained attention; specifically, waste-derived carbon materials like hydrochar are used as a potential nutrient recovery option and the nutrient-laden hydrochar can be disposed of as a slow release nutrient fertilizer (Oumabady et al., 2021). With this prelude, this study focuses on the integration of Electrochemical and UV Oxidation processes in the presence of Fenton's reagent with an aim to reduce the Chemical Oxygen Demand (COD), Total Organic Carbon (TOC) and Total Dissolved Solids (TDS) contents of the pharmaceutical effluent.

\section{MATERIAL AND METHODS}

\section{Sample collection}

The effluent was collected from the solvent extraction plant of $\mathrm{M} / \mathrm{s}$ Orchid Chemicals and Pharmaceuticals Ltd., Alathur, Chennai, Tamil Nadu, India. The effluent was collected in air tight PPFE containers and stored at $4{ }^{\circ} \mathrm{C}$ for further characterization.

\section{Jar test}

A preliminary Jar test (Table 1) has been conducted for solid-liquid separation using polymeric coagulants and flocculants and the efficient one has been selected for further analysis. Lime, Alum, and Poly aluminum chloride (PAC) are used as coagulants and CHEMPURE 9150 is used as Flocculants. The test jar-3 was selected and further used for the study.

\section{Experimental Setup}

The experiment was carried out in a laboratory equipped with an electrochemical cell, UV reactor and filters for the EO and UV oxidation. The effluent was circulated through a dual media filter (DMF), UV Reactor, and EO Reactor for 60 minutes. The final treated effluent was passed through an activated carbon filter (ACF). The samples were taken for analysis in the regular interval $(15,30,45 \& 60$ minutes).

\section{Electrochemical oxidation reactor}

Electrochemical oxidation was carried out in a batch recirculation setup of $5 \mathrm{~L}$ capacity with constant agitation and temperature control (Fig. 1). The cells were powered by a manually controlled $0.3 \mathrm{~kW}(12 \mathrm{~V} / 25 \mathrm{~A}) \mathrm{DC}$ power supplier (rectifier) with proper electrical connections. The anode and cathode used for the study were titanium coated plate and SS316 plate, respectively, with dimensions of $125 \mathrm{~mm} \times 100 \mathrm{~mm}$ and a current density of 1000 $\mathrm{Am}^{-2}$ at an electrode gap of $8 \mathrm{~mm}$.

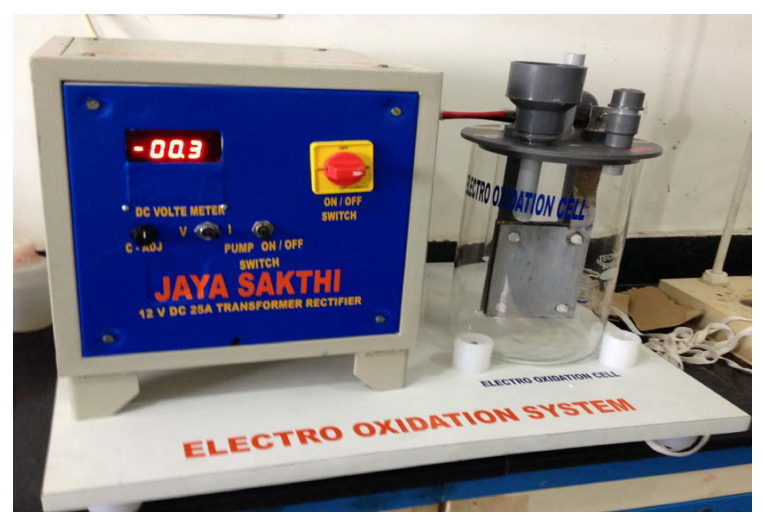

Fig 1. Electrochemical oxidation reactor

\section{UV reactor}

Design tests were performed to measure the UV dosage required to achieve the desired effluent concentration. The dosage to be applied to a particular stream is determined iteratively by examining the effect on the treatment of selected process variables such as $\mathrm{pH}$, oxidant concentration, and choice of catalyst. A $13 \mathrm{~W}$ powered OSRAM/ mercury UV lamp was used with a wastewater flow rate of 1 to $2 \mathrm{~L} \mathrm{~h}^{-1}$ at a wavelength of $254 \mathrm{~nm}$ (Fig. 2).

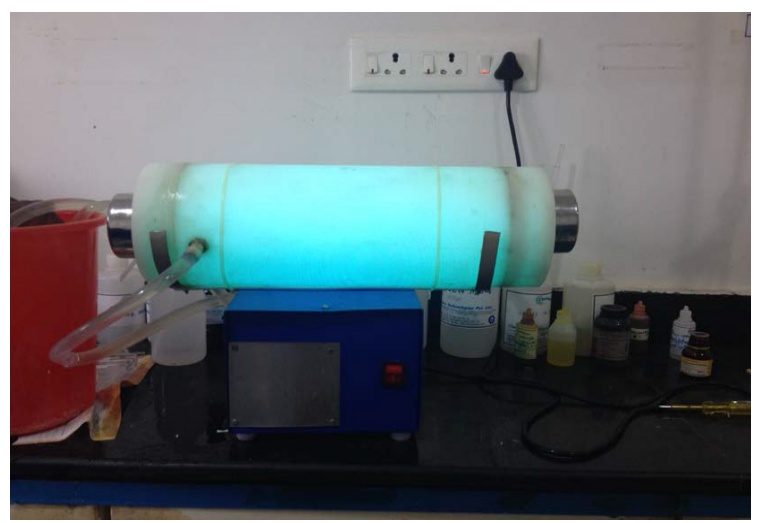

Fig 2. UV reactor

Fenton's reagent

The reagent was prepared by dissolving $2.48 \mathrm{~g}$ of $\mathrm{Fe}_{2} \mathrm{SO}_{4}$ in $200 \mathrm{~mL}$ distilled water and adjusting the $\mathrm{pH}$ between 4 and 5 using $0.01 \mathrm{~N} \mathrm{H}_{2} \mathrm{SO}_{4}$, followed by adding $6 \mathrm{~mL}$ of $\mathrm{H}_{2} \mathrm{O}_{2}$ into the solution.

\section{Experimental trials}

The batch experiments of the advanced oxidation process were conducted by integrating electrochemical oxidation (EO), UV oxidation (UV), and Fenton's reagent at different $\mathrm{pHs}$. The $\mathrm{pH}$

$107|10-12| 2$ 
adjustments were performed by $1 \mathrm{M} \mathrm{HCl}$ and $1 \mathrm{M}$ $\mathrm{NaOH}$ solutions. The trials conducted for the current study are presented in Table 2.

\section{RESULTS AND DISCUSSION \\ Characteristics of raw effluent}

The chemical characterization of raw effluent is listed in Table 3. The pH of the effluent was slightly alkaline with higher salinity. The total solids and COD of the effluent were also higherthat pave the way for the treatment through advanced oxidation process.

\section{Jar test experiment}

The selected jar test experiment results using the effluent are listed in Table 3. The color and turbidity of the sample were much reduced while the COD reduction was less than $12 \%$ which indicated the non-suitability of clarification with the coagulant.

Table 1. Details of preliminary jar test experiments

\begin{tabular}{|c|c|c|c|}
\hline Description & Test Jar - 1 & Test Jar - 2 & Test Jar -3 \\
\hline Sample volume (ml) & 1000 & 1000 & 1000 \\
\hline Lime Dosage (mg L $\mathrm{L}^{-1}$ ) & 300 & 500 & 600 \\
\hline Coagulant dosage (mg L $\left.\mathrm{L}^{-1}\right)$ & Alum 200 & Alum 300 & PAC 300 \\
\hline Polymer solution (Chempure-9150) (g L $\left.{ }^{-1}\right)$ & 1 & 1 & 1 \\
\hline Polymer dosage $\left(\mathrm{mg} \mathrm{L}^{-1}\right)$ & 1 & 1 & 1 \\
\hline Initial agitation time @ 100rpm (minutes) & 3 & 3 & 3 \\
\hline Floc size & Smaller & Larger & Larger \\
\hline Settling rate & Slow & Slow & Fast \\
\hline Settle sludge volume & $2 \%$ & $3 \%$ & $2 \%$ \\
\hline Supernatant color & Pale yellowish & Colorless & Colorless \\
\hline Supernatant clarity & Slightly turbid & Slightly turbid & Clear \\
\hline TSS in supernatant $\left(\mathrm{mgL}^{-1}\right)$ & 11.2 & 8.4 & 1.2 \\
\hline Compactness of the settled sludge & Fine particles & Fine particles & Fine particles \\
\hline Overall efficiency & Not considerable & Not considerable & Considerable \\
\hline COD of the supernatant effluent $\left(\mathrm{mgL}^{-1}\right)$ & 2040 & 2018 & 1878 \\
\hline
\end{tabular}

\section{Batch experiments}

The advanced oxidation process encompasses unique treatment technologies whose integration can lead to the efficient removal of the contaminants that remain persistent over a period of time. A combined EO \& UV oxidation system can be installed prior to the biological system in the case of effluents contaminated with recalcitrant (Gadipelly et al., 2014). It has been observed that there has been a high rate of oxidation within 15 minutes in all the trials. The rate of oxidation has gradually reduced for higher circulation time. However, more circulation time (60 minutes) has given better COD and TOC

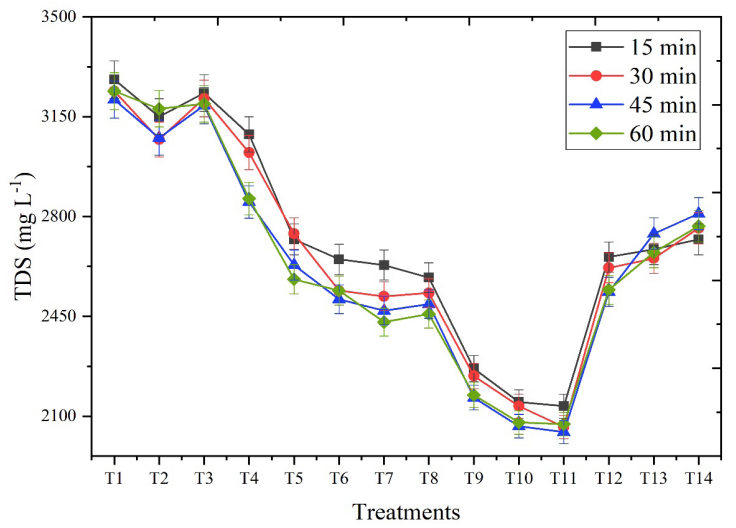

Fig 3. Effect of trials on TDS with respect to reaction time

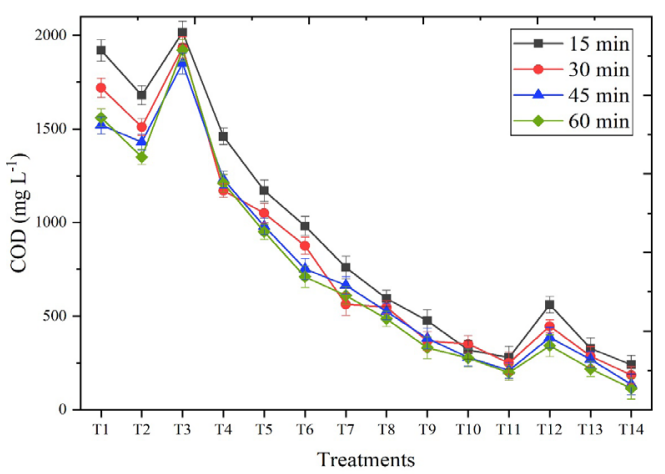

Fig 4. Effect of trials on COD with respect to reaction time

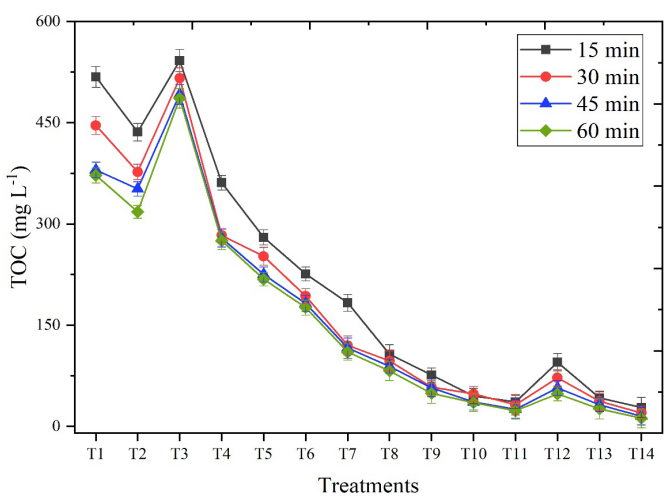

Fig 5. Effect of trials on TOC with respect to reaction time 
removal performance. The $\mathrm{pH}$ of the substrate has played a significant role throughout the process. Increased substrate $\mathrm{pH}$ accounts for efficient removal of pollutants (Murugananthan et al., 2007).

Table 2. Trial details for the advanced oxidation process

\begin{tabular}{|c|c|}
\hline Treatment & Details \\
\hline $\mathrm{T}_{1}$ & EO at pH 8.65 \\
\hline $\mathrm{T}_{2}$ & $\mathrm{EO}+\mathrm{UV}$ at $\mathrm{pH} 8.65$ \\
\hline$T_{3}$ & UV + Fenton's reagent $\left(100 \mathrm{mg} \mathrm{L}^{-1}\right)$ at $\mathrm{pH} 8.65$ \\
\hline $\mathrm{T}_{4}$ & $\mathrm{EO}+\mathrm{UV}+$ Fenton's reagent $\left(50 \mathrm{mg} \mathrm{L}^{-1}\right)$ at $\mathrm{pH} 8.65$ \\
\hline $\mathrm{T}_{5}$ & $\mathrm{EO}+\mathrm{UV}+$ Fenton's reagent $\left(100 \mathrm{mg} \mathrm{L}^{-1}\right)$ at $\mathrm{pH} 8.65$ \\
\hline $\mathrm{T}_{6}$ & $\mathrm{EO}+\mathrm{UV}+$ Fenton's reagent $\left(150 \mathrm{mg} \mathrm{L}^{-1}\right)$ at $\mathrm{pH} 8.65$ \\
\hline $\mathrm{T}_{7}$ & $\mathrm{EO}+\mathrm{UV}+$ Fenton's reagent $\left(200 \mathrm{mg} \mathrm{L}^{-1}\right)$ at $\mathrm{pH} 8.65$ \\
\hline $\mathrm{T}_{8}$ & $\mathrm{EO}+\mathrm{UV}+$ Fenton's reagent $\left(250 \mathrm{mg} \mathrm{L}^{-1}\right)$ at $\mathrm{pH} 8.65$ \\
\hline $\mathrm{T}_{9}$ & $\mathrm{EO}+\mathrm{UV}+$ Fenton's reagent $\left(300 \mathrm{mg} \mathrm{L}^{-1}\right)$ at $\mathrm{pH} 8.65$ \\
\hline $\mathrm{T}_{10}$ & $\mathrm{EO}+\mathrm{UV}+$ Fenton's reagent $\left(400 \mathrm{mg} \mathrm{L}^{-1}\right)$ at $\mathrm{pH} 8.65$ \\
\hline $\mathrm{T}_{11}$ & $\mathrm{EO}+\mathrm{UV}+$ Fenton's reagent $\left(500 \mathrm{mg} \mathrm{L}^{-1}\right)$ at $\mathrm{pH} 8.65$ \\
\hline $\mathrm{T}_{12}$ & $\mathrm{EO}+\mathrm{UV}+$ Fenton's reagent $\left(500 \mathrm{mg} \mathrm{L}^{-1}\right)$ at $\mathrm{pH} 7.5$ \\
\hline $\mathrm{T}_{13}$ & $\mathrm{EO}+\mathrm{UV}+$ Fenton's reagent $\left(500 \mathrm{mg} \mathrm{L}^{-1}\right)$ at $\mathrm{pH} 6.5$ \\
\hline $\mathrm{T}_{14}$ & EO + UV + Fenton's reagent $\left(500 \mathrm{mg} \mathrm{L}^{-1}\right)$ at $\mathrm{pH} 5.5$ \\
\hline
\end{tabular}

This is confirmed in trial 11 , wherein higher $\mathrm{pH}$ condition (8.65) has mediated towards the efficient removal of the contaminants from the pharmaceutical effluent. Moreover, higher circulation time has also contributed towards a cumulative removal of the contaminants with higher removal efficiency, as depicted in Fig. 3, 4, and 5.

Table 3. Characteristics of raw and treated effluent after Jar test

\begin{tabular}{|c|c|c|}
\hline Parameters & Raw sample & Treated sample \\
\hline Appearance & Slightly turbid & Clear \\
\hline Color & Pale yellowish & Colorless \\
\hline Odor & Characteristic & Odorless \\
\hline Turbidity, NTU & $18.4 \pm 0.8$ & $1.2 \pm 0.05$ \\
\hline $\mathrm{pH}$ & $8.65 \pm 0.25$ & $7.50 \pm 0.22$ \\
\hline Electrical Conductivity, $\mathrm{dSm}^{-1}$ & $5.77 \pm 0.17$ & $4.84 \pm 0.14$ \\
\hline Total Solids, mg L-1 & $3506 \pm 70.1$ & $3437.4 \pm 68.7$ \\
\hline TSS, mg L $\mathrm{L}^{-1}$ & $46 \pm 1.15$ & $3.4 \pm 0.085$ \\
\hline TDS , mg L $\mathrm{L}^{-1}$ & $3460 \pm 121.1$ & $3432 \pm 120.1$ \\
\hline $\mathrm{BOD}$ as $\mathrm{O}_{2}, \mathrm{mg} \mathrm{L}^{-1}$ & $354 \pm 14.16$ & $318.3 \pm 12.72$ \\
\hline TOC as $\mathrm{C}, \mathrm{mg} \mathrm{L}^{-1}$ & $573 \pm 21.74$ & $488.3 \pm 18.5$ \\
\hline $\mathrm{COD}, \mathrm{mg} \mathrm{L}^{-1}$ & $2120 \pm 84.5$ & $1878 \pm 75.3$ \\
\hline
\end{tabular}

The desirable result was achieved in trial 11 reducing COD and TOC to $90 \%$ (Fig. 6). This was due to the combined influence of electrochemical oxidation and UV oxidation with the help of Fenton's reagent as a catalyst. The removal of TOC from $\geq 90 \%$ to $\leq 3 \%$ denoted the efficiency of a different combination of trials with EO and UV oxidation.
Usage of Boron doped diamond has attained 97\% TOC removal at $300 \mathrm{~mA}$, in line with the experiment conducted (Brillas et al., 2010).

Table 5. Chemical Oxygen Demand for the treatments

\begin{tabular}{|c|c|c|c|c|}
\hline & $15 \mathrm{~min}$ & $30 \mathrm{~min}$ & $45 \mathrm{~min}$ & $60 \mathrm{~min}$ \\
\hline $\mathrm{T}_{1}$ & $1920^{b}$ & $1720^{b}$ & $1520^{b}$ & $1560^{b}$ \\
\hline $\mathrm{T}_{2}$ & $1680^{\circ}$ & $1510^{\circ}$ & $1430^{\circ}$ & $1350^{\circ}$ \\
\hline $\mathrm{T}_{3}$ & $2016^{a}$ & $1935^{a}$ & $1850^{a}$ & $1921^{a}$ \\
\hline $\mathrm{T}_{4}$ & $1460^{d}$ & $1170^{d}$ & $1230^{d}$ & $1210^{d}$ \\
\hline $\mathrm{T}_{5}$ & $1170^{e}$ & $1050^{e}$ & $980^{\mathrm{e}}$ & $950^{e}$ \\
\hline $\mathrm{T}_{6}$ & $982^{f}$ & $876^{f}$ & $752^{f}$ & $710^{f}$ \\
\hline $\mathrm{T}_{7}$ & $760^{g}$ & $563^{g}$ & $664^{g}$ & $610^{g}$ \\
\hline $\mathrm{T}_{8}$ & $594^{h}$ & $547^{g}$ & $525^{h}$ & $485^{h}$ \\
\hline $\mathrm{T}_{9}$ & $476^{i}$ & $367^{i}$ & $380^{i}$ & $331^{i}$ \\
\hline $\mathrm{T}_{10}$ & $320^{j k}$ & $351^{i}$ & $280^{j}$ & $276^{j}$ \\
\hline $\mathrm{T}_{11}$ & $278^{\mathrm{kl}}$ & $249^{j}$ & $210^{k}$ & $198^{k}$ \\
\hline $\mathrm{T}_{12}$ & $561^{\mathrm{h}}$ & $446^{h}$ & $385^{i}$ & $342^{i}$ \\
\hline $\mathrm{T}_{13}$ & $327^{j}$ & $285^{j}$ & $268^{j}$ & $218^{k}$ \\
\hline $\mathrm{T}_{14}$ & $240^{\prime}$ & $185^{k}$ & $136^{\prime}$ & $114^{\prime}$ \\
\hline
\end{tabular}

Optimum residence time of 77 minutes has mediated towards complete removal of TOC from pharmaceutical effluent (Domínguez et al., 2011) so that it was clear that residence time of more than 60 minutes favors complete removal of the contaminants from the effluent.

\section{Table 6. Total Organic Carbon content for the} treatments

\begin{tabular}{|c|c|c|c|c|}
\hline & $15 \mathrm{~min}$ & $30 \mathrm{~min}$ & $45 \mathrm{~min}$ & $60 \mathrm{~min}$ \\
\hline$T_{1}$ & $518^{b}$ & $446^{b}$ & $380^{b}$ & $372^{b}$ \\
\hline $\mathrm{T}_{2}$ & $436^{\circ}$ & $377^{\circ}$ & $352^{\circ}$ & $318^{c}$ \\
\hline $\mathrm{T}_{3}$ & $542^{a}$ & $516^{a}$ & $492^{a}$ & $486^{a}$ \\
\hline $\mathrm{T}_{4}$ & $361^{d}$ & $283^{d}$ & $279^{d}$ & $275^{d}$ \\
\hline $\mathrm{T}_{5}$ & $280^{e}$ & $252^{e}$ & $225^{e}$ & $218^{e}$ \\
\hline $\mathrm{T}_{6}$ & $226^{f}$ & $193^{f}$ & $182^{f}$ & $176^{f}$ \\
\hline $\mathrm{T}_{7}$ & $183^{g}$ & $120^{g}$ & $116^{g}$ & $110^{\mathrm{g}}$ \\
\hline $\mathrm{T}_{8}$ & $107^{\mathrm{h}}$ & $97^{\mathrm{h}}$ & $89^{h}$ & $82^{h}$ \\
\hline $\mathrm{T}_{9}$ & $76^{j}$ & $58^{j}$ & $57^{i}$ & $49^{i}$ \\
\hline $\mathrm{T}_{10}$ & $45^{k}$ & $48^{j k}$ & $36^{j}$ & $35^{j}$ \\
\hline $\mathrm{T}_{11}$ & $36^{\mathrm{kl}}$ & $32^{\mathrm{Im}}$ & $25^{\mathrm{jk}}$ & $23^{k}$ \\
\hline $\mathrm{T}_{12}$ & $95^{i}$ & $72^{i}$ & $57^{i}$ & $48^{i}$ \\
\hline$T_{13}$ & $42^{k}$ & $37^{\mathrm{kl}}$ & $32^{j}$ & $26^{k}$ \\
\hline $\mathrm{T}_{14}$ & $28^{\prime}$ & $20^{\mathrm{m}}$ & $15^{k}$ & $12^{\prime}$ \\
\hline
\end{tabular}

\section{CONCLUSION}

Combination of EO \& UV oxidation can be efficiently used for pharmaceutical effluent treatment in TOC and COD removal processes where biological treatment is not recommended. The use of hybrid technologies has been proved to be mandatory for the treatment of pharmaceutical compounds which are not completely eradicated by the single-stage treatment. The operation cost is Rs.33.75 $\mathrm{m}^{-3}$, acceptable in current industrial treatment practice. The combined EO \& UV oxidation treatment can be studied with various other 
industrial effluent and can be implemented. More risk assessment studies should be performed to investigate the ecological effects of pharmaceuticals and their metabolites. Future studies should consider developing AOP degradation protocols on mixtures of pharmaceuticals, given that they do not occur individually in water bodies.

\section{Funding and Acknowledgment}

The authors are thankful to the Department of Environmental Sciences, Tamil Nadu Agricultural University for providing laboratory and characterization facilities.

\section{Ethics statement}

No specific permits were required for the described field studies because no human or animal subjects were involved in this research.

\section{Originality and plagiarism}

Authors ensure that the manuscript has been written and submitted only entirely original works,

\section{Consent for publication}

All the authors agreed to publish the content.

\section{Competing interests}

The authors declare no competing interests.

\section{Data availability}

All the data of this manuscript are included in the MS. No separate external data source is required. If anything is required from the MS, certainly, this will be extended by communicating with the corresponding author through corresponding official mail; paulsebastian.s@tnau.ac.in

\section{Author contributions}

Idea conceptualization - PS, SB; Experiments SB; Guidance - PS; Writing-original draft - SO, PS, SB; Writing- reviewing \& editing - VD, PK.

\section{REFERENCES}

Boroski, M., Rodrigues, A. C., Garcia, J. C., Sampaio, L. C., Nozaki, J., and Hioka, N. 2009. Combined electrocoagulation and $\mathrm{TiO}(2)$ photoassisted treatment applied to wastewater effluents from pharmaceutical and cosmetic industries. $J$ Hazard Mater., 162(1): 448-454. doi: 10.1016/j. jhazmat.2008.05.062

Brillas, E., Garcia-Segura, S., Skoumal, M., and Arias, C. 2010. Electrochemical incineration of diclofenac in neutral aqueous medium by anodic oxidation using Pt and boron-doped diamond anodes. Chemosphere., 79(6): 605-612. doi: 10.1016/j. chemosphere.2010.03.004
Domínguez, J. R., González, T., Palo, P., Sánchez-Martín, J., Rodrigo, M. A., and Sáez, C. 2011. Electrochemical Degradation of a Real Pharmaceutical Effluent. Water, Air, \& Soil Pollution., 223(5): 2685-2694. doi: 10.1007/s11270-011-1059-3

Frank-Andreas Weber, T. a. D. B., Axel Bergmann, Alexander Carius, Gregor Grüttner, Silke Hickmann, Ina Ebert, Arne Hein, Anette Küster, Johanna Rose, Juliane Och-Jugl, Hans-Christian Stolzenberg. 2014. Policy issue on Pharmaceuticals in the environment - the global perspective. germany: Fedaral ministry for the environment, natural conservation, building and nuclear safety.

Gadipelly, C., Pérez-González, A., Yadav, G. D., Ortiz, I., Ibáñez, R., Rathod, V. K., and Marathe, K. V. 2014. Pharmaceutical Industry Wastewater: Review of the Technologies for Water Treatment and Reuse. Industrial \& Engineering Chemistry Research., 53(29): 11571-11592. doi: 10.1021/ie501210j

Garcia-Segura, S., Ocon, J. D., and Chong, M. N. 2018. Electrochemical oxidation remediation of real wastewater effluents - A review. Process Safety and Environmental Protection., 113: 48-67. doi: 10.1016/j.psep.2017.09.014

Huang, H., Guo, G., Tang, S., Li, B., Li, J., and Zhao, N. 2020. Persulfate oxidation for alternative sludge treatment and nutrient recovery: An assessment of technical and economic feasibility. Journal of Environmental Management., 272: 111007.

Kulik, N., Trapido, M., Goi, A., Veressinina, Y., and Munter, R. 2008. Combined chemical treatment of pharmaceutical effluents from medical ointment production. Chemosphere., 70(8): 1525-1531. doi: 10.1016/j.chemosphere.2007.08.026

Moreira, F. C., Boaventura, R. a. R., Brillas, E., and Vilar, V. J. P. 2017. Electrochemical advanced oxidation processes: A review on their application to synthetic and real wastewaters. Applied Catalysis B: Environmental., 202:217-261. doi: 10.1016/j. apcatb.2016.08.037

Murugananthan, M., Yoshihara, S., Rakuma, T., Uehara, N., and Shirakashi, T. 2007. Electrochemical degradation of 17 -estradiol (E2) at borondoped diamond (Si/BDD) thin film electrode. Electrochimica Acta, 52(9), 3242-3249. doi: 10.1016/j.electacta.2006.09.073

Nidheesh, P. V., Zhou, M., and Oturan, M. A. 2018. An overview on the removal of synthetic dyes from water by electrochemical advanced oxidation processes. Chemosphere., 197: 210-227. doi: 10.1016/j.chemosphere.2017.12.195

Oumabady, S., Selvaraj, P. S., Kamaludeen, S. P., Ettiyagounder, P., and Suganya, K. 2021. Application of sludge-derived $\mathrm{KOH}$-activated hydrochar in the adsorptive removal of orthophosphate. RSC Advances., 11(12): 6535-6543. 